\title{
A Simple Moist Model Relevant to the Origin of Intraseasonal Disturbances in the Tropics*
}

\author{
By Toshio Yamagata \\ Research Institute for Applied Mechanics, Kyushu University, Kasuga 816, Japan \\ (Manuscript received 10 November 1986, in revised form 21 January 1987)
}

\begin{abstract}
A simple moist model useful to understand some basic properties relevant to the origin of the intraseasonal disturbances in the tropics is constructed by use of the linear shallow-water equations on a sphere. The dynamical equations are supplemented by the moisture equation as proposed by Gill (1982). The mutual interaction of equatorial dynamics and convective activity is demonstrated by releasing localized, initial anomalies for either temperature or velocity. In particular, it is found that there are two intrinsic ways of large-scale moist adjustment processes in the tropics.

Firstly, it is shown that the active heating region associated with the convergence of low-level winds propagates eastward spontaneously with expanding the zonal scale of the velocity field. The phase speed of this organized pattern is much smaller than that of the corresponding free Kelvin wave because the buoyancy effects are much reduced by the convergence-dependent heating. These results are consistent with the recent observational studies of the 30-50 day oscillation in the tropics.

Secondly, the present model also demonstrates that the burst of westerly winds may excite a westward propagating cross-equatorial cyclone pair more easily than the burst of easterly winds. This vortex pair is mainly composed of the gravest Rossby waves with moist processes and is quite similar to the long-lived synoptic cyclone pair often observed over the warm SST region in the tropics.
\end{abstract}

\section{Introduction}

The intraseasonal disturbance in the tropical atmosphere was discovered first by Madden and Julian $(1971,1972)$ in the early 1970's. Since then, the existence of this interesting phenomenon, which is now often given the name $30-50$ day oscillation, has been confirmed by numerous observational works. Those are, for example, Parker (1973), Yasunari (1979, 1980), Krishnamurti and Subrahmanyam (1982), Maruyama (1982), Murakami et al. (1984), Lorenc (1984), Lau and Chan (1985). In particular, Madden and Julian (1972) introduced an illuminating interpretation that the disturbance is due to an eastward migration of the enhanced large-scale convective activity over the warm SST region

\footnotetext{
*This paper was presented at "International Seminar on Studies of Large-Scale Atmospheric Processes by Use of Models" (Kyoto, July 1986).
}

(c) 1987 Meteorological Society of Japan from the Indian ocean to the dateline. This picture was confirmed recently by Lau (1985) by use of the OLR data. In other words, the disturbance may be regarded more appropriately as the event associated with short-term eastward migration of the updraft branch of the Walker circulation over the warm SST region. One may interpret, in the above sense, that kind of intraseasonal disturbance as a miniature of the interannual Southern Oscillation event (Yamagata and Hayashi, 1984). However, its rapid eastward propagation suggests the dominance of the atmospheric wave dynamics rather than the oceanic wave dynamics. In other words, the role of the ocean for the intraseasonal disturbance may be a very limited one such as a slave to the atmosphere (cf. McPhaden, 1982; Mysak and Mertz, 1984). This presents a striking contrast to the El Niño/Southern Oscillation (ENSO) phenomena during which the air-sea interaction 
with a positive feedback plays a crucial role in determining the slow eastward migration of both warm SST region and updraft region of the Walker circulation (Philander et al., 1984); Yamagata, 1985; Hirst, 1986).

There is another type of intraseasonal disturbances in the tropics (Gray, 1979). That is the cyclone pair event associated with strong westerly bursts over the warm SST region. Although it must be a phenomenon of equal importance, much less attention has been paid as compared with its counterpart called the 30-50 day oscillation. Only one detailed study up to now was done by Keen (1982). Interestingly enough, he suggested the possibility that this type of synoptic event may trigger the El Niño/Southern Oscillation event. Luther et al. (1983) also suggested that a series of strong westerly bursts lasting 1 to 3 weeks may force equatorial Kelvin waves in the ocean that can both initiate and sustain the ENSO phenomena. Recently, based on the FGGE Level III-b data produced by ECMWF, Ogura and Chin (1986) confirmed the importance of low-level equatorial westerlies when the tropical cyclone pair formed on January 2,1979 .

In the present paper, therefore, we first direct our attention to the manner in which the enhanced cumulus activity associated with the intraseasonal disturbance propagates eastward rather rapidly over the warm SST region without any direct air-sea coupling. Then, as a counterpart to this type of intraseasonal disturbance, we show how a westward propagating cross-equatorial cyclone pair is generated during the process of moist-dynamical adjustment. The compact model solely for these purposes is adapted from Gill (1982) and described briefly in Section 2. Section 3 presents some simple numerical solutions relevant to the origin of those rather longlived atmospheric disturbances. Discussion is given in the final section.

\section{The model atmosphere}

In order to understand the basic mechanism which gives rise to rather long-lived atmospheric disturbances described in the introduction, we shall modify the simple model of Gill (1980) by including the interaction of convective heating and low-level convergence. The crucial assump- tion of the above Gill's model is that the vertical structure is described by a single vertical mode. This limitation was discussed by Geisler and Stevens (1982) and Yamagata and Hayashi (1984). The second crucial assumption is that the effect of the latent heating is given externally so that the interaction of convection and low-level winds is completely neglected. The third assumption is that strong damping of momentum is necessary for the purpose of explaining the observed flow patterns within the framework of a linear theory (cf. Sardeshmukh and Held, 1984). Despite those limitations of the simple model, Gill (1980) could explain successfully the basic structure of the Walker circulation in response to the prescribed heating. Here we shall relax the above second assumption in a manner as simple as possible by including the moisture equation. This type of simple model was also proposed originally by Gill (1982) for an $f$-plane case and developed recently by Davey (1985) and Davey and Gill (1986). In particular, Davey and Gill (1986) investigated the steady response of the tropical atmosphere to the idealized Pacific SST patterns. In the present work, we shall discuss how initial disturbances evolve by a process of moist-dynamical adjustment in the tropics.

The rudiments of the basic model are given by Gill (1982). Here we begin with the equations for a primitive, one-mode atmosphere on a sphere. The linearized momentum equations have the form

$$
\begin{aligned}
& \frac{\partial u}{\partial t}-f v=-\frac{1}{\rho_{a}} \frac{\partial p}{a \cos \phi \partial \lambda}-\varepsilon u, \\
& \frac{\partial v}{\partial t}+f u=-\frac{1}{\rho_{a}} \frac{\partial p}{a \partial \phi}-\varepsilon v,
\end{aligned}
$$

where $(u, v)$ denote the horizontal velocities at the lower troposphere, $p$ the pressure perturbation, $\rho_{a}$ air density, $f$ the Coriolis parameter, and $a$ is the radius of the earth. Variables $(\lambda, \phi)$ represent longitude and latitude. The constant $\varepsilon$ is the coefficient for Rayleigh damping. Assuming the hydrostatic balance leads to the equation which relates $p$ with the potential temperature perturbation $\theta$. This has the form

$$
p=-\rho_{a} g H_{0} \theta / \theta_{0},
$$


where $g$ is the acceleration due to gravity, $H_{0}$ is the depth of the lower troposphere and $\theta_{0}$ is the typical potential temperature. The mass continuity for the lower troposphere takes the form

$$
\frac{\partial u}{a \cos \phi \partial \lambda}+\frac{\partial v}{a \partial \phi}+\frac{w}{H_{0}}=0 \text {, }
$$

where $w$ is the vertical velocity at the middle level of the troposphere. The potential temperature at the middle level is governed by

$\frac{\partial \theta}{\partial t}+\frac{\theta_{0} N^{2}}{g} w=Q-\gamma \theta$,

where $N$ is the buoyancy frequency, $\gamma$ is the coefficient of Newtonian cooling, $Q$ is the heating rate. The heating rate $Q$ is related to the precipitation rate $P$ in the following form.

$$
Q=\rho_{w} L_{c} P /\left(\rho_{a} H_{0} C_{p}\right),
$$

where $\rho_{w}$ is the water density, $L_{c}$ is the latent heat of condensation and $C_{p}$ is the specific heat of air at constant pressure. The precipitation rate $P$ is predicted by the equation which governs the moisture perturbation per unit area:

$$
\begin{aligned}
\bar{q}\left(\frac{\partial u}{a \cos \phi \partial \lambda}+\frac{\partial v}{a \partial \phi}\right) & =-P \\
\text { for } q & =\bar{q} \text { and } w>0,
\end{aligned}
$$

and

$$
\begin{aligned}
& \frac{\partial q}{\partial t}+\bar{q}\left(\frac{\partial u}{a \cos \phi \partial \lambda}+\frac{\partial v}{a \partial \phi}\right)=-\delta(q-\bar{q}), \\
& \quad \text { for } q<\bar{q} \text { or } q=\bar{q} \text { and } w<0,
\end{aligned}
$$

where $\bar{q}$ is the moisture per unit area for which the atmosphere is just saturated. One should note here that the above (2.6) is of nonlinear character. Also notice that the quantity $\delta$ is a measure of the relaxation process for the moisture content. In other words, evaporation always makes the air saturated within a time scale of $\mathrm{O}\left(\delta^{-1}\right)$. We assume the higher SST gives rise to the larger value of $\delta$ according to Bjerknes (1966)'s hypothesis.

Now it is convenient to introduce a new quantity $h$ defined by

$$
h \equiv \frac{H_{0} \theta}{\theta_{0}}\left(=-\frac{p}{\rho_{a} g}\right),
$$

Then, the potential temperature equation (2.4) can be replaced by

$$
\begin{aligned}
& \frac{\partial h}{\partial t}-H_{e}\left(\frac{\partial u}{a \cos \phi \partial \lambda}+\frac{\partial v}{a \partial \phi}\right)=-\gamma h, \\
& \quad \text { for } q<\bar{q} \text { or } q=\bar{q} \text { and } w<0,
\end{aligned}
$$

and

$$
\begin{array}{r}
\frac{\partial h}{\partial t}+\left(H_{m}-H_{e}\right)\left(\frac{\partial u}{a \cos \phi \partial \lambda}+\frac{\partial v}{a \partial \phi}\right)=-\gamma h, \\
\text { for } q=\bar{q} \text { and } w<0, \quad(2.8 \mathrm{~b})
\end{array}
$$

where the equivalent depth $H_{e}\left(=N^{2} H_{0}{ }^{2} / \mathrm{g}\right)$ and the negative equivalent depth due to moist processes $H_{m} \quad\left(=\rho_{w} L_{c} q /\left(\rho_{a} \theta_{0} C_{p}\right)\right)$ are used for simplicity.

In the next section solutions of the above system composed of a set of evolution equations (2.1), (2.6) and (2.8) are obtained for some initial conditions with using a numerical method, which is described briefly in Appendix I.

\section{Some numerical solutions}

\subsection{Evolution of an initial temperature anom- aly}

In this subsection we prescribe a localized temperature anomaly initially. The profile is given tentatively by

$$
\theta_{i}=A \exp \left\{-\left(\frac{\lambda-120^{\circ}}{30^{\circ}}\right)^{2}-\left(\frac{\phi}{10^{\circ}}\right)^{2}\right\},
$$

where $A$ is the amplitude of the initial disturbance. For the present experiment, $A$ is set to $\theta_{0} / 8$. The necessary values of other parameters are the equivalent depth $H_{e}=400 \mathrm{~m}$, the mean moisture content $\bar{q}=4.5 \mathrm{~cm}$, and the equivalent depth due to a moisture effect $H_{m}=360 \mathrm{~m}$. These values ensure that our moist process is stable. This is because the effective equivalent depth $\left(H_{e}-H_{m}\right)$ is kept positive. In other words, the warming due to the latent heat release is smaller than the cooling due to vertical advection of sensible heat (see Gill, 1982). The damping coefficients $\varepsilon$ and $\gamma$ are set to 0.2 /day.

Figure 1 shows the evolution of the zonal velocity $u$ and the precipitation rate $P$ right on the equator for the parameter value $\delta=2 /$ day. The heating region associated with the intermittent precipitation propagates eastward with a phase speed $(=20.0 \mathrm{~m} / \mathrm{s})$, which is much smaller than the adiabatic Kelvin wave speed $(=62.6$ 

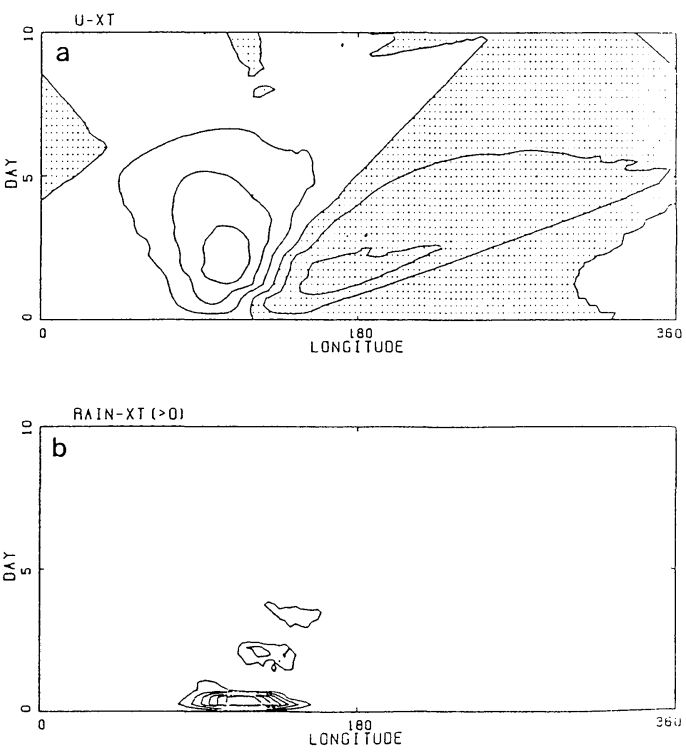

Fig. 1. (a) Time evolution of the zonal velocity along the equator. The initial perturbation is the temperature anomaly. Shaded regions indicate westward flow. Contour interval $=2 \mathrm{~m} / \mathrm{s}$. (b) As in (a) but for the precipitation rate. Contour interval $=1.0 \times 10^{-5}$ $\mathrm{cm} / \mathrm{s}$. See text for details.

$\mathrm{m} / \mathrm{s}$ ). Since the eastern edge of the easterly corresponds to the downdraft region and propagates as the adiabatic Kelvin wave, the zonal scale of the easterly extends as time goes on. Similarly, as the adiabatic Rossby wave propagates westward, the zonal scale of the westerly also extends as time goes on. Therefore, one may conclude that the above "red cascade" of the zonal scale is an intrinsic property of the mutual interaction between the latent heat release and the equatorial wave dynamics in our formulation. The slow eastward movement of the central updraft region may be explained by the reduction of buoyancy effects due to the convergence-dependent heating (cf. Gill, 1982). The direction of this movement is determined by the excited Kelvin wave because of its strong convergence on and near the equator although the-whole structure of the updraft region is composed of the forced Kelvin and Rossby waves. Therefore, the slow phase speed is given by $\sqrt{g\left(H_{t}-H_{m}\right)}$. Notice here that the above Kelvin response is enhanced further by the eastward movement of the heating region itself as shown in Appendix II.

The intermittency of the precipitation is due to the divergence associated with the inertia- gravity waves excited initially. The period of the gravest meridional mode of which wavelength is about $60^{\circ}$ in longitude is about 19 hours for the westward propagating mode and about 21 hours for the eastward propagating mode (Matsuno, 1966). This is consistent with the simulated active and break interval of the precipitation.

Figure 2 shows the evolution of pressure, wind and moisture fields. It can be seen that the initial temperature anomaly excites Rossby (Kelvin) waves to the west (east) of the heating region. At Day 2, the wind vector pattern is quite similar to the steady state response of Gill (1980). As time goes on, the main part of the heating region moves spontaneously eastward with increasing the zonal scale for both easterly and westerly and then attenuates due to dissipation. The westward propagating Rossby response with rather weak heating in the extratropics is also detectable in the figure. The latter type of response is remarkable for an initial westerly anomaly and so it is discussed in the next subsection.

It is of interest to see the case in which supply of the moisture is not so efficient. This situation somehow reflects the condition over a low SST region or a continent. Figure 3 shows the evolution of the zonal velocity $u$ and the precipitation rate $P$ right on the equator for the parameter value $\delta=0.2 /$ day. Since the relaxation time for the moisture is much increased, the evaporation is not so active now to recover the saturation level of moisture in the region exposed to the downdraft beforehand. This means that the latent heat release associated with the convergent winds is much reduced. Therefore, the initial response disperses rather quickly into westward propagating Rossby waves and an eastward propagating Kelvin wave. This result is similar to Figure 3 of Philander et al. (1984), in which the initial perturbation disperses into free adiabatic equatorial modes when the air-sea coupling is switched off.

\subsection{Evolution of an initial velocity anomaly}

In this subsection we discuss the evolution of an initial velocity anomaly. We assume the velocity disturbance as

$$
u_{i}=B \exp \left\{-\left(\frac{\lambda-120^{\circ}}{30^{\circ}}\right)^{2}-\left(\frac{\phi}{10^{\circ}}\right)^{2}\right\},
$$



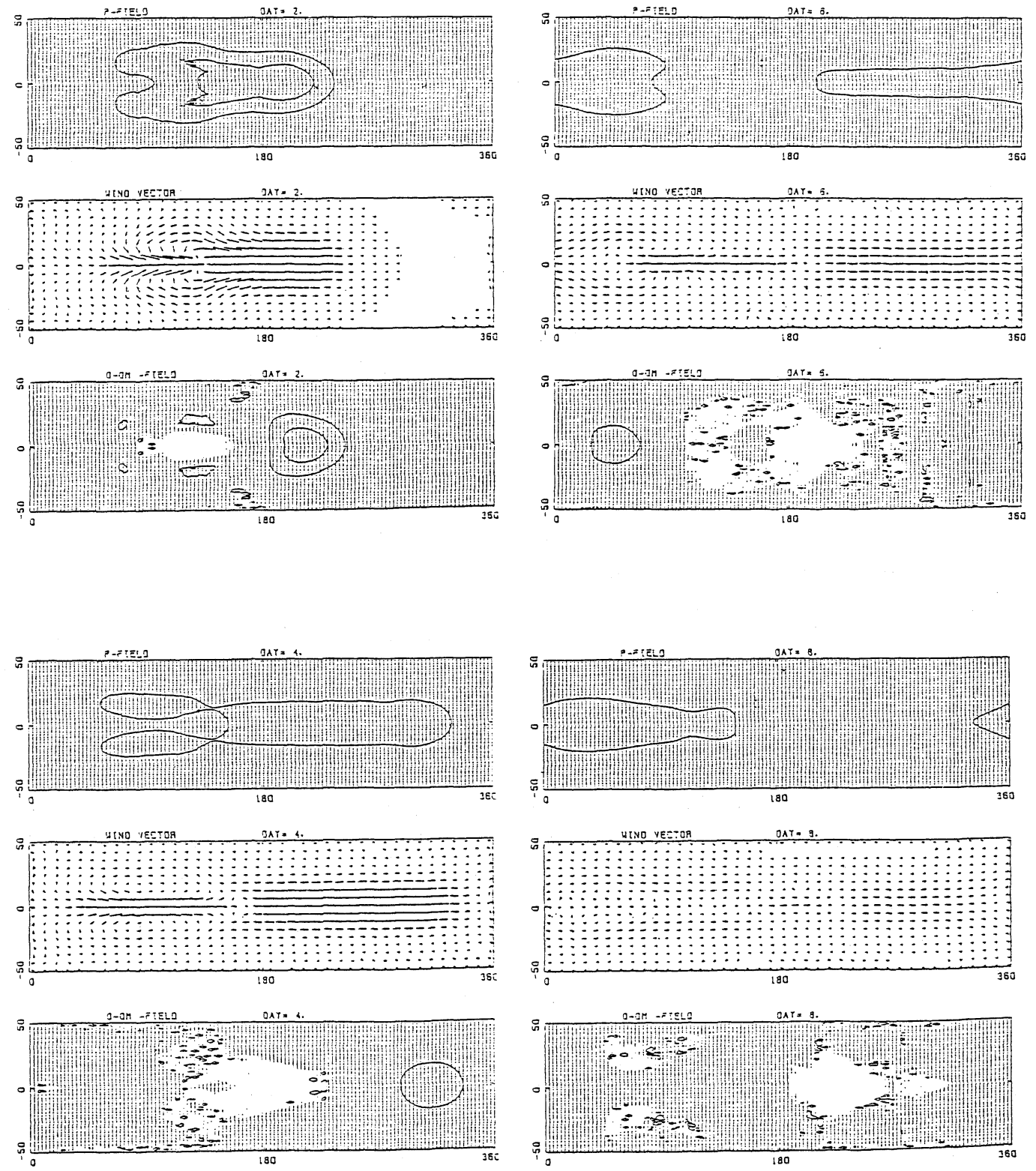

Fig. 2. Time evolution of pressure, wind and moisture fields for Fig. 1. The contour interval is $10 \mathrm{~m}$ for pressure and $0.05 \mathrm{~cm}$ for moisture. Shaded regions indicate negative values. See text for details.

where $B$ is the amplitude of the disturbance, of which absolute value is set to $20 \mathrm{~m} / \mathrm{s}$ in our simulation. The parameter values are the same as those of the previous subsection.

Figure 4 shows the longitude-time plot of the zonal velocity right on the equator for the case of the initial westerly burst. Also shown in the same figure is the purely adiabatic case. Comparing those two cases, it can be seen that the excitation of a Kelvin wave is extremely suppressed during the moist adjustment process. This result can be easily expected by inspecting well-known Gill pattern for the stationary response to the equatorial heating. Since the heating induced by the initial low-level wind convergence is located at the eastern edge for the westerly burst, the main part of kinetic energy must be imparted to the Rossby modes which 

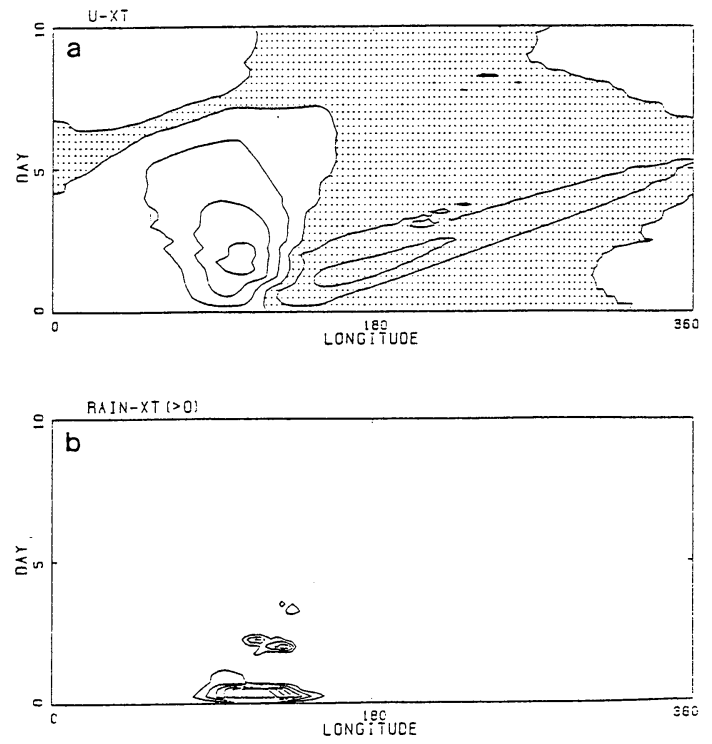

Fig. 3. As in Fig. 1 but for a longer relaxation time of the moisture with $\delta=0.2 /$ day.
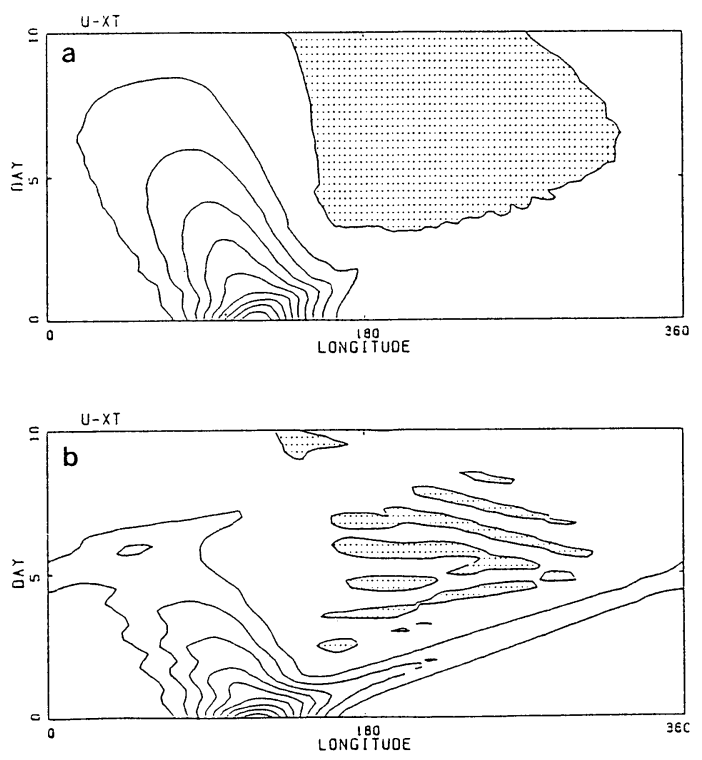

Fig. 4. As in Fig. 1 (a) but for the initial westerly burst. (a) The diabatic case. (b) The adiabatic case.

propagate westward (see also Appendix II). Figure 5 shows the evolution of pressure, wind vector and moisture fields. A pair of cyclones, which is composed of the gravest Rossby mode, can be seen clearly, whereas the Kelvin response is very weak. This may be one typical way of large-scale moist adjustment processes in the equatorial atmosphere.

The case for the initial easterly burst, however, takes a quite different course of evolution. This is demonstrated in Figures 6 and 7. In contrast to the westerly case, the excitation of Rossby waves is remarkably suppressed during the adjustment process. Instead, the Kelvin wave trailing a heating region associated with the weak Rossby wave response west of it propagates eastward. This result can be also interpreted qualitatively by use of the Gill pattern. The heating induced by the initial low-level wind convergence is located at the western edge for the easterly burst. The consequence is that the main part of kinetic energy must be imparted to the Kelvin wave which propagates eastward from the forcing region (see Appendix II). As shown in Section 3.1 , the zonal scale of the easterly associated with the Kelvin wave expands as time goes on. This structure is quite similar to the mode discussed in Section 3.1 and demonstrates again the other typical way of large-scale moist adjustment processes in the equatorial atmosphere.

\section{Summary and discussion}

We have integrated a simple conceptual model numerically in order to show two important ways of large-scale moist adjustment processes in the tropics. First, we demonstrated that the initial positive temperature anomaly excites Rossby (Kelvin) waves to the west (east) of the heating region. As time goes on, the heating region moves eastward with increasing the zonal scale of both easterly and westerly. The apparent "red cascade" of the zonal scale may explain why the 30-50 day oscillation is zonally of global nature (cf. Madden and Julian, 1972). The initial eastward movement of the convective region is explained by the dominance of the divergence associated with the Kelvin response over that of the Rossby response. In other words, the asymmetric response of the tropical atmosphere even to a localized, symmetric heating is a key factor of the eastward propagation (cf. Philander et al., 1984). As shown in Appendix II, the above tendency is enhanced by the eastward movement of the heating region itself. The phase speed of this eastward moving updraft branch of the Walker-type circulation is much smaller than that of the adiabatic Kelvin wave, 

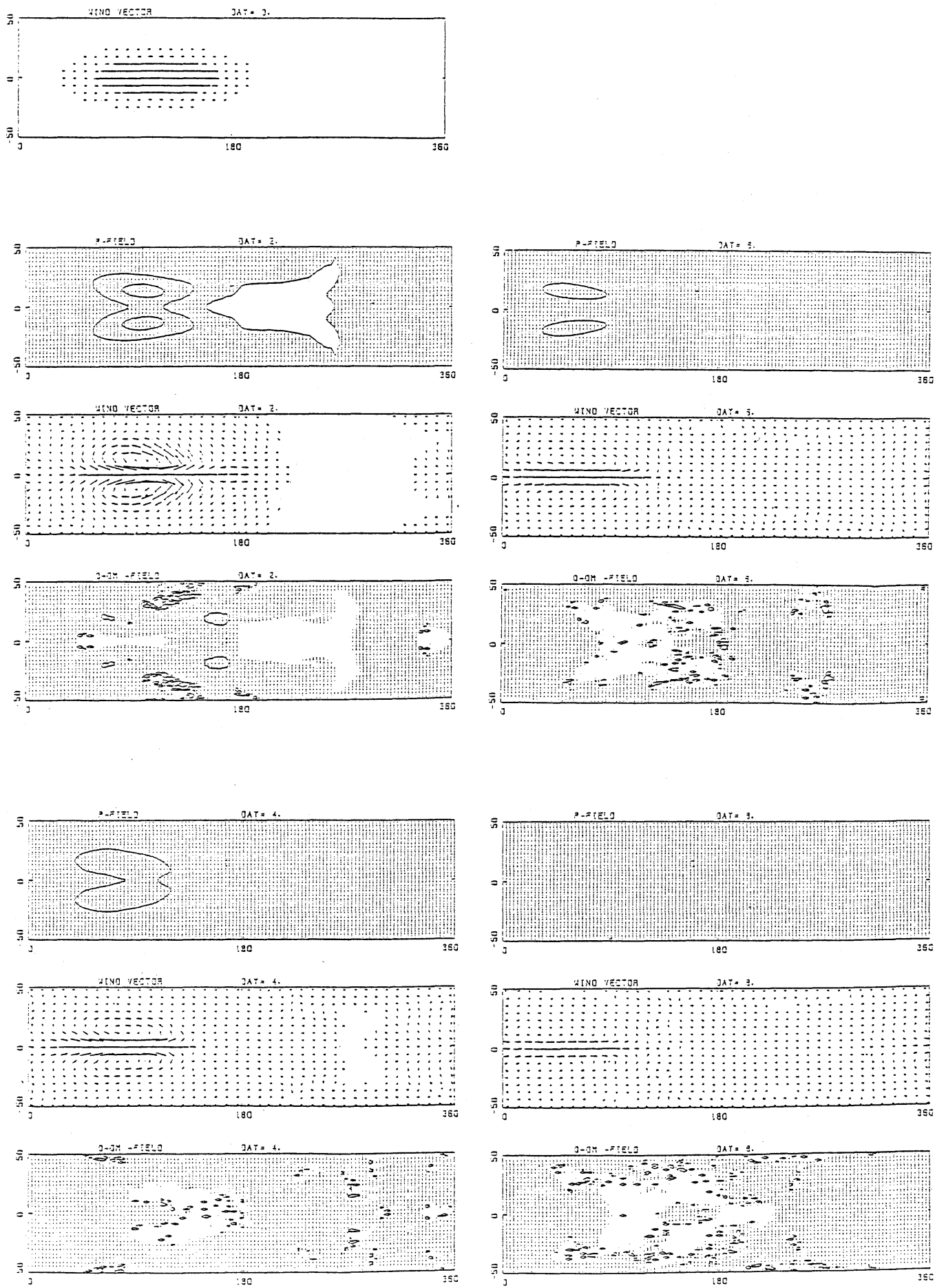

Fig. 5. As in Fig. 2 but for Fig. 4 (a). 

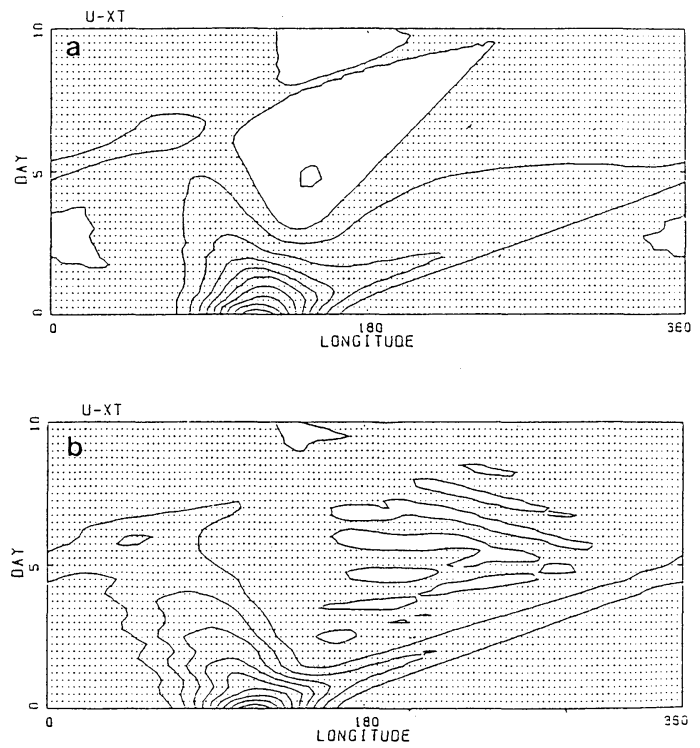

Fig. 6. As in Fig. 1 (a) but for the initial easterly burst. (a) The diabatic case. (b) The adiabatic case.

which is consistent with the observation (Madden and Julian, 1972; Parker, 1973). One should note that all these results are intrinsic to the mutual interaction of the latent heat release and the equatorial wave dynamics.

The experiment in which supply of the moisture is not efficient shows the quick dispersion into free equatorial waves. This is because the insufficient moisture supply weakens the heating which excites the Kelvin response and the Rossby response. This may explain, at least qualitatively, why the large negative OLR (which is a good indicator of convective cloudiness and precipitation) associated with the 30-50 day oscillations often appears only over the warm SST region (cf. Lau,1985).

Secondly, we investigated the evolution of an initial velocity anomaly. In particular, the case for the westerly burst nicely demonstrates the other way of large-scale moist adjustment processes in the tropics. There, a westward moving cross-equatorial cyclone pair associated with the latent heat release is shown to be easily formed across the equator, whereas the Kelvin response is extremely suppressed by the westward movement of the heating region. This cyclone pair is mainly composed of the gravest equatorial Rossby waves with moist processes and is quite similar to the long-lived twin vortex often ob- served in the western Pacific (Palmer, 1952; Keen, 1982; Kimura, 1983; Ogura and Chin, 1986).

So far we have several attempts to explain the 30-50 day oscillation in the tropics. Parker (1973) tried to explain the eastward propagation within the framework of the equatorial Kelvin wave theory. However, he failed to explain the slow eastward propagation of the disturbance over the high SST region from the Indian Ocean to the dateline. As a remedy for the wave theory, Chang (1977) took account of the effects of Rayleight friciton and Newtonian cooling. However, he failed to explain the most important aspect of the oscillation, that is, the eastward propagation of the enhanced large-scale convective activity over the warm SST region. The first work which paid attentions to this convective heating is Yamagata and Hayashi (1984). However, they assumed a priori that the oscillation is forced by a prescribed heat source over the warm SST region. Recently, Y-Y. Hayashi and Sumi (1986), Hayashi and Golder (1986) and Lau and Lau (1986) have succeeded in simulating some aspects of the intraseasonal oscillations with GCM models. In particular, Hayashi and Golder (1986) found that their GCM results are in good agreement with the FGGE data in space-time spectrum. With a simplified GCM, Y-Y. Hayashi and Sumi (1986) suggested that the intraseasonal oscillation is a new mode of the equatorial waveCISK problem and showed the importance of the moist processes in maintaining the mode. This aspect of their conclusion is consistent with our simple conceptual model results although our mode decays because of the stable moist process. Lau and Peng (1986) have also succeeded in developing numerical model for the origin of the oscillation without treating moisture processes explicitly. They also pointed out the importance of the interaction of convection and dynamics in maintaining the eastward propagating Kelvinlike disturbance.

Comparing to those models, the present one appears to be too simple. However, its ability to model some basic dynamical and thermodynamical aspects of the intraseasonal disturbances is highly encouraging and deserves serious attention. This is because conceptual models may be as simple as possible, if they aim at pinpointing 

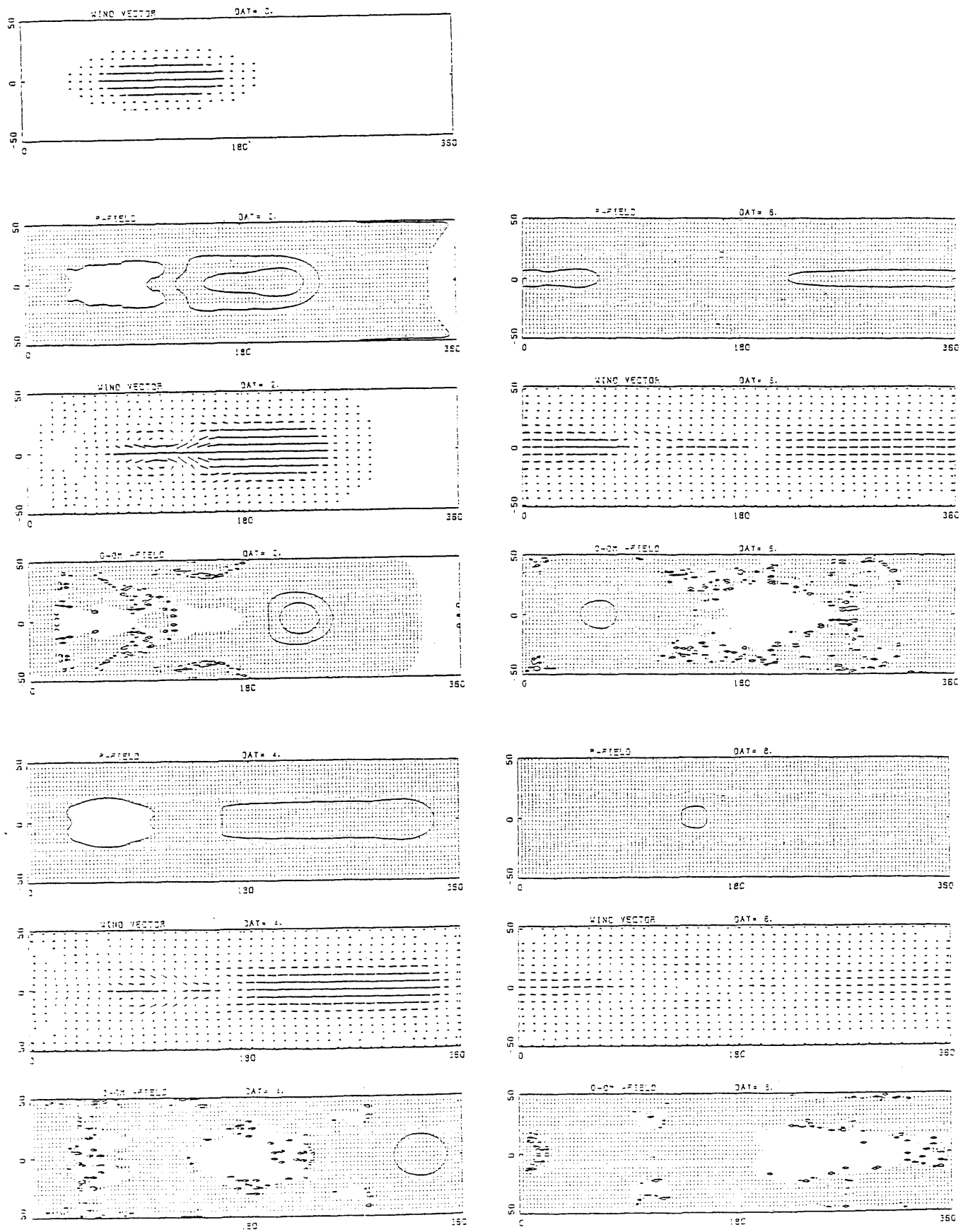

Fig. 7. As in Fig. 2 but for Fig. 6.

a root cause of the phenomenon. In addition, based on our conceptual model results, we believe it is of equal importance to study the counterpart of the intraseasonal disturbances, that is, the westward propagating long-lived cyclone pair over the warm SST region. The latter might play a significant role during the initial stage of the El Niño/Southern Oscillation events 
as suggested by Keen (1982) and Luther et al. (1983). Since the westerly burst associated with the cyclone pair can generate a warm SST anomaly in the western Pacific by modulating the zonal gradient of the SST field, it may evolve easily into the large-scale air-sea coupled mode with a positive feedback (Yamagata, 1986).

\section{Acknowledgements}

I am grateful to Drs. M. Davey, Y. Hayashi, Y-Y. Hayashi, R. Kimura, K. M. Lau, S. Miyahara, M. Takahashi and Y. Wakata for useful communication while preparing the manuscript. I also thank Mr. S. Umatani for computer assistance and Miss K. Motomatsu for typing the manuscript. The present work is supported in part by the Japan Ministry of Education, Science and Culture under Contract \#61302024 and the Toray Science Foundation.

\section{Appendix I}

\section{The numerical model}

The numerical model used in this paper is constructed by use of a shallow water model originally developed by the GFDL oceanic circulation group (cf. Bryan, 1969). The model equations are solved in a zonal channel which extends from $50^{\circ} \mathrm{S}$ to $50^{\circ} \mathrm{N}$. The $120 \times 100$ grid points are spaced regularly so that the zonal and meridional grid sizes are $3^{\circ}$ and $1^{\circ}$, respectively.

\section{Appendix II}

A simple extension of Gill's model for the moving heat source

Here we adapt Gill's (1980) solution for the case in which the heating moves with a uniform speed $C$ in the zonal direction. The basic equations with the equatorial beta-plane approximation and the long wave approximation can be written

$$
\begin{aligned}
& \frac{\partial u}{\partial t}-\frac{1}{2} y v=-\frac{\partial p}{\partial x}-\varepsilon u, \\
& \frac{1}{2} y u=-\frac{\partial p}{\partial y}, \\
& \frac{\partial p}{\partial t}+\frac{\partial u}{\partial x}+\frac{\partial v}{\partial y}=-Q-\gamma p,
\end{aligned}
$$

where $u, v, p$ and $Q$ are the zonal velocity, the meridional velocity, the pressure, the mass source or sink (which corresponds to the heating rate). The quantities $\varepsilon$ and $\gamma$ are the Rayleigh friction and Newtonian cooling coefficients which are assumed to be equal. The above system is nondimensionalized by using as a length scale the equatorial Rossby radius $\left(C_{0} / 2 \beta\right)^{1 / 2}$ and as a time scale $\left(2 \beta C_{0}\right)^{-1 / 2}$, where $C_{0}\left(=\left(g H_{e}\right)^{1 / 2}\right)$ is the long gravity wave speed.

As in Gill (1980) we prescribe the localized heating $Q$ but now $Q$ moves eastward with a uniform speed $C$ as the following:

$$
\begin{aligned}
& Q=F(X) \exp \left(-y^{2} / 4\right), \\
& \begin{array}{c}
F(X)=\cos k X, \quad|X| \leqq L, \\
=0, \quad X>L,
\end{array}
\end{aligned}
$$

where $k=\pi /(2 L)$ and $X=x-C t$. By using the moving coordinate $X$, the above equations can be reduced to

$$
\begin{aligned}
& -C \frac{\partial u}{\partial X}-\frac{1}{2} y v=-\frac{\partial p}{\partial X}-\varepsilon u, \\
& \frac{1}{2} y u=-\frac{\partial p}{\partial y}, \\
& -C \frac{\partial p}{\partial X}+\frac{\partial u}{\partial X}+\frac{\partial v}{\partial y}=-Q-\varepsilon p .
\end{aligned}
$$

Following Gill (1980), we can readily write down the solution of our problem as

$$
\begin{aligned}
& u=\frac{1}{2}\left[q_{0}+q_{2}\left(y^{2}-3\right)\right] \exp \left(-y^{2} / 4\right), \\
& v=\left[F(X)+4 \varepsilon q_{2}\right] y \exp \left(-y^{2} / 4\right),
\end{aligned}
$$

and

$$
p=\frac{1}{2}\left[q_{0}+q_{2}\left(1+y^{2}\right)\right] \exp \left(-y^{2} / 4\right),
$$

where the Kelvin part $q_{0}$ and Rossby part $q_{2}$ are given by

$$
\begin{aligned}
{\left[\varepsilon^{2}+\right.} & \left.(1-C)^{2} k^{2}\right] q_{0}(X) \\
= & 0 \text { for } X<-L, \\
= & -\varepsilon \cos k X-(1-C) k[\sin k X \\
& \left.+\exp \left\{-\frac{\varepsilon}{1-C}(X+L)\right\}\right] \\
& \quad \text { for }|X| \leqq L,
\end{aligned}
$$




$$
\begin{aligned}
= & -(1-C) k\left\{1+\exp \left(-\frac{2 \varepsilon L}{1-C}\right)\right. \\
& \left.\cdot \exp \left\{\frac{\varepsilon}{1-C}(L-X)\right\}\right\} \\
& \text { for } X>L,
\end{aligned}
$$

and

$$
\begin{aligned}
{\left[9 \varepsilon^{2}+\right.} & \left.(1+3 C)^{2} k^{2}\right] q_{2}(X) \\
= & -(1+3 C) k\left[1+\exp \left\{-\frac{6 \varepsilon L}{1+3 C}\right\}\right] \\
& \cdot \exp \left\{\frac{3 \varepsilon}{1+3 C}(X+L)\right\} \\
& \quad \text { for } X<-L \\
= & -3 \varepsilon \cos k X \\
+ & (1+3 C) k[\sin k X \\
& \left.-\exp \left\{\frac{3 \varepsilon}{1+3 C}(X-L)\right\}\right] \\
& \text { for }|X| \leqq L, \\
= & 0 \text { for } X>L .
\end{aligned}
$$

Figure A1 shows the Kelvin response $q_{0}$ at $X=L$ and the Rossby response $q_{2}$ at $X=-L$ as a function of $C$ for $\varepsilon=0.043$ (which corresponds to $0.2 \mathrm{day}^{-1}$ in dimensional form) and $L=2.9$ (which corresponds to $30^{\circ}$ in dimensional form). For $C \sim 1$ the Kelvin wave responds resonantly, whereas the gravest Rossby wave responds reasonantly for $C \sim-\frac{1}{3}$. Except for these resonant cases, the Kelvin (Rossby) response increases (decreases) monotonically with increasing $\mathrm{C}$ within the range $-\frac{1}{3}<C<1$. This explains why the Kelvin (Rossby) response is strengthened (weakened) when the heating moves eastward and vice versa when the heating moves westward.

\section{References}

Bjerknes, J., 1966: A possible response of the atmospheric Hadley circulation to equatorial anomalies of ocean temperature. Tellus, 18, 820-828.

Bryan, K., 1969: A numerical method for the study of the circulation of the World Ocean. J. Comput. Phys., 4, 347-376.

Chang, C-P., 1977: Viscous internal gravity waves and low frequency oscillations in the tropics. J. Atmos. Sci., 34, 901-910.

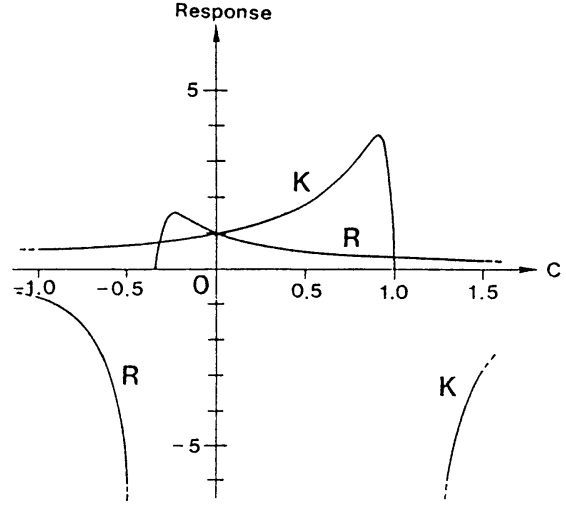

Fig. A1. Effect of moving heat source on the response of Gill's (1980) model. The capital K denotes the Kelvin response $q_{0}$ at $X=L$. The capital $\mathrm{R}$ denotes the Rossby response $q_{2}$ at $X=-L$. Each response is normalized by using the value at $c=0$.

Davey, M.K., 1985: Results from a moist equatorial atmosphere model. In: Coupled Ocean-Atmosphere Models (ed. J.C.J. Nihoul). Elsevier Oceanography Series, 40, 41-49. and A.E. Gill, 1986: Experiments on tropical circulation with a simple moist model. To be submitted.

Geisler, J.E. and D.E. Stevens, 1982: On the vertical structure of damped steady circulation in the tropics Quart. J. Roy. Met. Soc., 108, 87-93.

Gill, A.E., 1980: Some simple solutions for heatinduced tropical circulation. Quart. J. Roy. Met. Soc., 106, 447-462.

, 1982: Studies of moisture effects in simple atmospheric models: the stable case. Geophys. Astrophys. Fluid Dynamics, 19, 119-152.

Gray, W.M., 1979: Hurricanes: Their formations, structure and likely role in the tropical circulation. Meteorology over the Tropical Oceans, Ed. D.B. Shaw, Roy. Meteor. Soc., Bracknell, Great Britain.

Hayashi, Y. and D.G. Golder, 1986: Tropical intraseasonal oscillations appearing in a GFDL general circulation model and FGGE data. Part I: Phase propagation. Submitted to J. Atmos. Sci.

Hayashi, Y-Y. and A. Sumi, 1986: The 30-40 day oscillations simulated in an "aqua planet" model. J. Met. Soc. Japan, 64, 451-467.

Hirst, A.C., 1986: Unstable and damped equatorial modes in simple coupled ocean-atmosphere models. J. Atmos. Sci., 43, 606-630.

Keen, R.A., 1982: The role of cross-equatorial tropical cyclone pairs in the Southern Oscillation. Mon. Wea. Rev., 110, 1405-1416.

Kimura, R., 1983: On the formation of tropical twin cyclones (in Japanese). Tenki, 30, 302-303.

Krishnamurti, T.N. and D. Subrahmanyam, 1982: The 30-50 day mode at $850 \mathrm{mb}$ during MONEX. $J$. 
Atmos. Sci., 39, 2088-2095.

Lau, K-M., 1985: Subseasonal scale oscillation, bimodal climatic state and the El Niño/Southern Oscillation. In: Coupled Ocean-Atmosphere Models (ed. J.C.J. Nihoul). Elsevier Oceanography Series, 40, 29-40. and P-H. Chan, 1985: Aspects of the 40-50

day oscillation during northern winter from outgoing longwave radiation. Mon. Wea. Rev., 113, 18891909.

Lau, N-C. and K-M. Lau, 1986: Structure and propagation of intraseasonal oscillations appearing in a GFDL GCM. J. Atmos. Sci., in press.

Lau, K-M. and L. Peng, 1986: Origin of low frequency (intraseasonal) oscillations in the tropical atmosphere. Part I: The basic theory. Submitted to J. Atmos. Sci.

Lorenc, A.C., 1984: The evolution of planetary scale $200 \mathrm{mb}$ divergence flow during the FGGE year. Quart. J. Roy. Met. Soc., 110, 427-441.

Luther, D.S., D.E. Harrison and R.A. Knox, 1983: Zonal winds in the central equatorial Pacific and El Niño. Science, 222, 327-330.

Madden, R.A. and P.R. Julian, 1971: Detection of a 40-50 day oscillation in the zonal wind in the tropical Pacific. J. Atmos. Sci., 28, 702-708.

and , 1972: Description of global scale circulation cells in the tropics with 40-50 day period. J. Atmos. Sci., 29, 1109-1123.

Maruyama, T., 1982: Upper tropospheric zonal wind oscillation with a 30-50 day period over the equatorial western Pacific observed in cloud movement vectors. J. Met. Soc. Japan, 60, 172-181.

Matsuno, T., 1966: Quasi-geostrophic motions in the equatorial area. J. Met. Soc. Japan, 44, 25-42.

McPhaden, M.J., 1982: Variability in the central equatorial Indian Ocean. Part I: Ocean dynamics. J. Mar. Res., 40, 157-176.

Murakami, T., T. Nakazawa and J. He, 1984: On the
40-50 day oscillations during the 1979 northern hemisphere summer. Part I: Phase propagation. $J$. Met. Soc. Japan, 62, 440-468.

Mysak, L.A. and G.J. Mertz, 1984: A 40 to 60 day oscillation in the source region of the Somali Current during 1976.J. Geophys. Res., 89, 711-715.

Ogura, Y. and H-N. Chin, 1986: A case study of longlived tropical vortices observed over the western Pacific in the northern winter using FGGE data. Submitted to J. Atmos. Sci.

Palmer, C., 1952: Tropical Meteorology. Quart. J. Roy. Met. Soc., 78, 126-164.

Parker, D.E., 1973: Equatorial Kelvin waves at 100 millibars. Quart. J. Roy. Met. Soc., 99, 116-129.

Philander, S.G.H., T. Yamagata and R.C. Pacanowski, 1984: Unstable air-sea interactions in the tropics. J. Atmos. Sci., 41, 604-613.

Sardeshmukh, P.D. and I.M. Held, 1984: The vorticity balances in the tropical upper troposphere of a general circulation model. J. Atmos. Sci., 41, 768-778.

Yamagata, T., 1985: Stability of a simple air-sea coupled model in the tropics. In: Coupled Ocean-Atmosphere Models (ed. J.C.J. Nihoul). Elsevier Oceanography Series, 40, 637-657.

, 1986: On the recent development of simple, coupled ocean-atmosphere models of ENSO. $J$. Oceanogr. Soc. Japan, 42, 299-307.

and Y. Hayashi, 1984: A simple diagnostic model for the 30-50 day oscillation in the tropics. J. Met. Soc. Japan, 62, 709-717.

Yasunari, T., 1979: Cloudiness fluctuations associated with the northern hemisphere summer monsoon. J. Met. Soc. Japan, 57, 227-242.

1980: A quasi-stationary appearance of 30 to 40 day period in the cloudiness fluctuations during the summer monsoon over India. J. Met. Soc. Japan, 58, 225-229. 


\title{
熱帯の季節内擾乱の起源に関する簡単な湿潤モデル*
}

\author{
山 形 俊 男 \\ (九州大学応用力学研究所)
}

熱帯大気の季節内擾乱の起源に関する基本的な性質を理解するために，球面上の浅水方程式を用いた モデルを作製した。Gill(1982）の提案に基づき，力学方程式と湿度方程式を結合させた。この系に初期 挸乱として温度あるいは速度の局在したアノマリ一を与え，その後の適応過程を調べた。特に，熱带域 の大規模な湿潤適応過程には重要な二形態があることがわかった。

まず，下層の風の収束に伴う加熱域は風系の東西スケールを拡張しながら，自発的に東進する。この 東進速度は収束に伴う加熱が浮力効果を減じるために，自由なケルビン波の位相の速さよりもはるかに 遅い。これらの結果は熱帯の30～50日振動に関する最近の観測結果と合致する。

次いで，西風の吹き出しが赤道をまたいで存在する低気圧性の渦対を容易に形成しうることを見い出 した。この渦対は湿潤過程を伴うロスビー波を主な要素としており，熱带域の高い海面水温域によく見 られる長寿命の低気圧性渦对に良く似ている。

* 本論文は大気力学京都国際セミナー（1986年 7 月）に於いて発表したものである。 